\title{
Viral quasispecies of hepatitis B virus in patients with YMDD mutation and lamivudine resistance may not predict the efficacy of lamivudine/adefovir rescue therapy
}

\author{
CHANGTAI WANG ${ }^{1,2}$, SHU YU $^{1}$, YAFEI ZHANG ${ }^{1}$, MIN ZHANG $^{3}$, LIYING LV $^{3}$, \\ CHENG HUANG ${ }^{4}, \mathrm{XU} \mathrm{LI}^{1}, \mathrm{JUN} \mathrm{LI}^{4}$ and ZHENHUA ZHANG ${ }^{1,4}$
}

\author{
${ }^{1}$ Department of Infectious Diseases, The Second Affiliated Hospital of Anhui Medical University, Hefei, Anhui 230601; \\ ${ }^{2}$ Department of Infectious Diseases, The Affiliated Anqing Hospital of Anhui Medical University, Anqing, Anhui 246000; \\ ${ }^{3}$ Department of Clinical Laboratory, The First Affiliated Hospital of Anhui Medical University; \\ ${ }^{4}$ College of Pharmacy, Anhui Medical University, Hefei, Anhui 230022, P.R. China
}

Received May 2, 2018; Accepted December 3, 2018

DOI: $10.3892 / \mathrm{etm} .2019 .7255$

\begin{abstract}
The association between hepatitis B virus (HBV) quasispecies (QS) and the efficacy of nucleos(t)ide analog therapy is currently not well defined, particularly in the case of lamivudine (LAM)/adefovir (ADV) combination rescue therapy for patients with chronic HBV infection (CHB) presenting with LAM resistance. In the present study, 16 CHB patients with the rtM204I/V mutation in the tyrosine-methionine-aspartate-aspartate motif of the $\mathrm{C}$ domain of the polymerase gene who switched to LAM/ADV treatment due to LAM resistance were assessed. HBV DNA was isolated from these patients and the reverse transcriptase (RT) region was sequenced. The QS heterogeneity and distribution was analyzed, the mutation sites were recorded and the phylogenetic trees were constructed. The results indicated that QS heterogeneity and distribution in the RT and $\mathrm{S}$ regions were not significantly different between responders (RS) and non-RS (NRS) at baseline $(\mathrm{P}>0.05)$, except for the higher frequency of a dominant strain in the RT region at the nucleotide level in the RS group ( $\mathrm{P}=0.039)$. In addition, in NRS, no significant difference in QS heterogeneity or distribution in these regions was identified at six months vs. the baseline. Furthermore, although in the non-responder group the frequency of the LAM resistance-associated mutations (rtM204V/I) decreased at 6 months compared with the baseline, it did not disappear in any of the patients after six months of treatment. Analysis of individual patients did not indicate any consistent selection of specific HBV mutants during LAM/ADV rescue therapy. In
\end{abstract}

Correspondence to: Professor Zhenhua Zhang, Department of Infectious Diseases, The Second Affiliated Hospital of Anhui Medical University, 678 Furong Road, Hefei, Anhui 230601, P.R. China E-mail: zzh1974cn@163.com

Key words: hepatitis B virus, lamivudine, adefovir, quasispecies, resistance mutation conclusion, the baseline HBV QS within the RT and S regions may not be a valid predictor of the response to LAM/ADV rescue treatment in CHB patients with LAM resistance.

\section{Introduction}

An estimated 240 million individuals worldwide are chronically infected with hepatitis B virus (HBV) (1). Large-scale studies have demonstrated that effective anti-viral therapy may inhibit HBV replication and hence remission of the liver disease, thereby preventing associated morbidity and mortality (2). In China, current treatments for chronic hepatitis $\mathrm{B}$ (CHB) include interferon (IFN)- $\alpha$ and nucleos(t)ide analogs (NAs). Five NA drugs, namely lamivudine (LAM), adefovir (ADV), telbivudine, entecavir (ETV) and tenofovir (TDF), have been approved for the treatment of CHB. A problem with NA therapy is that a long duration of treatment leads to an increased risk of drug resistance, which subsequently results in treatment failure. Although LAM and ADV are not recommended as first-line therapy in CHB, they are administered to numerous patients with $\mathrm{CHB}$, either as a monotherapy or in combination, due to reasons including low cost and availability (3). As a result, drug resistance remains a great challenge in HBV treatment.

LAM was the first nucleoside analogue approved for the treatment of CHB. Resistance to LAM has been reported in $\sim 20 \%$ of anti-viral-naive patients after one year and up to $70 \%$ of patients after five years of treatment (4). It has been indicated that LAM resistance is mostly associated with the rtM204I/V mutation in the tyrosine-methionine-aspartate-aspartate (YMDD) motif of the $\mathrm{C}$ domain of the polymerase gene. Several types of rescue therapy have been applied in patients with LAM-resistant $\mathrm{CHB}$, yielding virological and biochemical improvements (5). A number of studies have reported good efficacy of LAM/ADV combination as a rescue therapy against LAM resistance $(6,7)$. However, ADV resistance was encountered in $~ 18 \%$ of the patients who had presented with resistance to LAM after 48 weeks of ADV administration (8). ADV-resistance has been associated with the rtN236T mutation in the D domain 
and/or the $\mathrm{rtA} 181 \mathrm{~V} / \mathrm{T}$ mutation in the B domain. However, the underlying mechanisms of the development of ADV resistance due to LAM/ADV combination therapy in patients with LAM resistance have remained elusive.

Although HBV is a DNA virus, it uses pre-genomic RNA as a replicative intermediate, similar to RNA viruses. The lack of proof-reading capacity of the HBV reverse transcriptase (RT) and a high replication rate result in a significantly increased frequency of viral genomic mutations (9). Consequently, the virus circulates as quasispecies (QS), a spectrum of genetically distinct but highly similar viral variants, and their evolution and distribution require to be monitored to allow for proper chronic infection management (10). QS may contribute to viral pathogenesis, and may have an influence on anti-viral treatment and an involvement in drug resistance, as has been reported previously for RNA viruses, including hepatitis $\mathrm{C}$ virus (HCV) and human immunodeficiency virus (HIV) $(11,12)$. Several studies have indicated that the HBV QS complexity may be associated with the virological response to NAs (13-16). However, the association between HBV QS and NA treatment is currently not well-defined, particularly in case of LAM/ADV combination therapy for LAM resistance.

Due to the overlap between the open reading frames of the RT and the HBV surface antigen (HBsAg), mutations in the RT domain frequently affect the amino acid sequence of the HBsAg, leading to immune evasion (17). Chen et al (18) reported changes in nucleotide or amino acid sequences in the $\mathrm{HBsAg}$ region in LAM and/or ADV resistance in LAM/ADV-treated patients. Dynamic changes in QS within the $S$ region may also have important roles. However, the impact of QS of the $S$ region on LAM/ADV combination therapy in LAM-resistant patients has largely remained to be elucidated. The present study aimed to investigate the evolution of HBV QS within the $\mathrm{RT}$ and $\mathrm{S}$ regions during six months of LAM/ADV combination anti-viral therapy in patients with YMDD mutation and LAM resistance, and to explore its effects on drug resistance and anti-viral efficacy.

\section{Materials and methods}

Study design. A total of 16 patients with CHB who received LAM/ADV combination as rescue therapy due to LAM resistance were enrolled at the First Affiliated Hospital of Anhui Medical University (Hefei, China) between July 2010 and August 2014. All patients were initially administered oral doses of LAM at $100 \mathrm{mg}$ per day (Glaxo Smith Kline Pharmaceuticals, Co., Ltd., Suzhou, China) and LAM plus ADV at $10 \mathrm{mg}$ per day (Glaxo Smith Kline Co., Ltd.), after the detection of LAM resistance-associated HBV variants. All patients received combination therapy for at least six months.

Patients who met the following inclusion criteria were enrolled: Age, 18-60 years; presence of HBsAg at least six months prior to LAM treatment; elevated HBV DNA $\geq 10^{5}$ copies/ml and serum alanine aminotransferase (ALT) levels higher than twice the upper limit of normal prior to LAM treatment; no history of receiving NAs or IFN treatment at any time prior to LAM treatment; and YMDD mutation confirmed by direct sequencing. The exclusion criteria were as follows: Co-infection with HIV, HCV or hepatitis D virus; liver diseases due to other causes (e.g., autoimmune liver disease, alcoholic hepatitis or drug-induced hepatitis); and poor compliance during treatment.

Anti-viral efficacy was evaluated at six months from the start of LAM/ADV combination treatment. Patients who had undetectable HBV DNA levels (HBV DNA <1,000 copies/ml) at six months were defined as responders (RS), while patients who did not meet this criterion were considered non-RS (NRS).

At baseline and at six months, serum samples were obtained from all 16 patients and stored at $-80^{\circ} \mathrm{C}$. Liver biochemistry, HBV serology and HBV DNA levels were determined at the First Affiliated Hospital of Anhui Medical University (Hefei, China), as described previously (19).

Molecular cloning and sequencing. HBV DNA was extracted from serum samples $(100 \mu \mathrm{l})$ using the QIAamp blood mini kit (cat.no. 40725; Qiagen GmbH, Hilden, Germany) following the manufacturer's instructions and eluted in $30 \mu \mathrm{l}$ distilled water. The nucleotide sequences of the HBV RT region were determined using a nested polymerase chain reaction (PCR) and direct sequencing. DNA was amplified using $5 \mathrm{U} / \mu 1$ Taq DNA polymerase (Takara Biotechnology Co., Ltd., Dalian, China), $5 \mu$ HBV DNA template, $1 \mu$ leach primer and $10 \mathrm{mMeach}$ dNTP in a final volume of $30 \mu \mathrm{l}$. A PCR reactor (Biometra TRIO 48; Biometra biomedizinische Analytik GmbH, Jena, Germany) was used. Primer sequences for the first round of PCR were forward, 5'-CCTGCTGGTGGCTCCAGTTCMG-3' (nt 58-79) and reverse, 5'-AGGAGTTCCGCAGTATGGATCGGCAG-3' (nt 1,286-1,260). The first round of PCR analysis was performed under the following conditions: initial denaturation at $95^{\circ} \mathrm{C}$ for $7 \mathrm{~min}, 35$ cycles of denaturation at $95^{\circ} \mathrm{C}$ for $30 \mathrm{sec}$, annealing at $57^{\circ} \mathrm{C}$ for $30 \mathrm{sec}$ and extension at $72^{\circ} \mathrm{C}$ for $90 \mathrm{sec}$, followed by a final elongation step $\left(7 \mathrm{~min}\right.$ at $\left.72^{\circ} \mathrm{C}\right)$. The primers used for the second round of PCR were forward, 5'-CCATATCGT CAATCTTMTCGA-3' (nt 113-134) and reverse, 5'-CCAGTG GGGGTTGCGTCAGCAA-3' (nt 1,208-1,186). The parameters for the second round were the same as the first. If the HBV DNA levels were $<10,000$ copies/ml, nested PCR was used to amplify the HBV RT region; if the HBV levels were $>10,000$ copies $/ \mathrm{ml}$, however, only the second round of PCR was performed. PCR products were resolved in $2 \%$ agarose gels by electrophoresis with ethidium bromide staining. A fragment of $\sim 1,100$ bp containing the entire RT region was amplified. PCR products were purified from the gels by using the Agarose Gel DNA Purification kit (Takara Bio Inc., Dalian, China) according to the manufacturer's instructions.

Purified PCR products were cloned into the pMD18-T vector (Takara Bio Inc.,) following the manufacturer's protocols. Positive clones were sequenced with two primers specific for the vector, RV-M and M13-47, on an ABI sequencing system (Applied Biosystems; Thermo Fisher Scientific, Inc., Waltham, MA, USA). For each sample, 25 clones were sequenced.

Sequence analysis. BioEdit 7.0.9 (20) was used to assemble sequences. Multiple alignments were performed on all sequences using Clustal X 2.0 (21). RDP3.0 software was used to detect potential recombinant sequences (22). QS complexity and diversity were determined and used to evaluate the dynamics of viral heterogeneity. QS complexity was measured via the Shannon entropy $(\mathrm{Sn})$, which refers to the number of variants identified in a single sample. The Sn 
was calculated at the nucleotide and amino acid level using the following formula: $\left.\mathrm{Sn}=-\sum \mathrm{i}(\mathrm{pi} \mathrm{x} \operatorname{lnpi})\right] / \ln \mathrm{N}$, where pi is the frequency of each clone in the QS population and $\mathrm{N}$ is the total number of clones (23). Three parameters were used to assess QS diversity: The mean genetic distance (d), the number of synonymous substitutions per synonymous site (dS), and the number of non-synonymous substitutions per non-synonymous site (dN). $d$ was calculated at the nucleotide and the amino acid level. $\mathrm{d}$ at the nucleotide level was calculated using Tamura's three-parameter model, whereas that at the amino acid level was calculated using the Jones-Taylor-Thornton model with Mega 7.0 software. The $\mathrm{dS}$ and $\mathrm{dN}$ values were calculated under the modified Nei-Gojobori model with Jukes-Cantor correction using Mega 7.0 software (24).

$H B V$ genotyping and phylogenetic analysis. In the present study, the HBV genotype was assigned by phylogenetic analysis of the $\mathrm{S}$ gene. Sequences were aligned with the Clustal W program. Phylogenetic trees were constructed by neighbour-joining analysis with 1,000 replicates of the bootstrap resampling test using Mega 7.0. Phylogenetic trees were constructed at baseline and six months of LAM/ADV combination treatment using all groups of sequences at the nucleotide and the amino acid level.

Statistical analysis. Continuous variables were expressed as the median and range. Multiple samples of the measurement data between different groups and time-points were compared by using the Kruskal-Wallis test, and the Mann-Whitney U-test was applied as a post-hoc test when appropriate. Categorical data were examined using the Chi-square test or Fisher's exact test. A two-tailed $\mathrm{P}<0.05$ was considered to indicate a statistically significant difference. Statistical analyses were performed using SPSS 17.0 (SPSS, Inc., Chicago, IL, USA).

\section{Results}

Demographic, clinical and laboratory data. The demographic data and clinical features of the patients are provided in Table I. Based on the serum HBV DNA levels, seven patients were identified to respond to LAM/ADV combination treatment, while nine were NRS and two experienced a virological breakthrough. Sex, age, HBeAg status, genotype, drug resistance under LAM treatment, YMDD pattern, ALT levels and HBV DNA levels in RS and NRS were comparable at baseline ( $P>0.05)$. No significant difference in ALT levels was identified in either group at months three and six, but HBV DNA levels in RS were lower than those in NRS (median, <3.00 vs. $4.20 \mathrm{lg}$ copies/ml, $\mathrm{P}=0.018$; median, $<3.00$ vs. $4.23 \mathrm{lg}$ copies $/ \mathrm{ml}, \mathrm{P}=0.001$, respectively) at months three and six (Table I). In the NRS group, 8 patients switched to ETV plus ADV, and only one patient continued to use LAM/ADV. At the 9-month follow-up, one patient decided to discontinue the treatment. At the 12-month follow-up, eight patients exhibited a virological response. Therefore, no further research was performed on these patients.

Viral $Q S$ in the $R T$ region and $S$ region. A total of 608 sequences (range, 21-26 per serum sample) were generated and analyzed. The characteristics of QS were analyzed for the RT and $\mathrm{S}$ gene region in each patient.
In the RT region, no significant difference in the QS composition was identified between RS and NRS at baseline, at either the nucleotide or the amino acid level. Compared with the QS composition prior to treatment, no change was observed at six months, not even in the NRS (P>0.05; Fig. 1). In the RT region, the number of QS and dominant strains exhibited no significant difference between RS or NRS at baseline and NRS at six months, at either the nucleotide or the amino acid level (all P>0.05; Fig. 2). The number of QS in RS was also similar to that in NRS at the baseline, at the nucleotide and the amino acid level $(\mathrm{P}=0.166$ and 0.594 , respectively; Fig. 2A and B). The frequency of the dominant strain in RS was significantly higher than that in NRS at the nucleotide level $(\mathrm{P}=0.039)$, but indistinguishable at the amino acid level $(\mathrm{P}=0.223$; Fig. 2C and D). QS complexity and diversity was not significantly different between RS and NRS at baseline and NRS at six months, at the nucleotide and the amino acid level in the RT region (all P>0.05; Fig. 3). QS complexity at baseline exhibited no significant difference between $\mathrm{RS}$ and NRS at the nucleotide and the amino acid level $(\mathrm{P}=0.138$ and 0.491, respectively; Fig. 3A and B). In the NRS group, the QS complexity at the baseline [0.7734 (0.4110-0.9680) and $0.6699(0.0000-0.9045)$ at the nucleotide and amino acid level, respectively] was not significantly different from that at six months [0.7961 (0.5294-0.9856) and 0.7654 (0.4235-0.9822) at the nucleotide and amino acid level, respectively; $\mathrm{P}=0.691$ and 0.627 , respectively]. The QS diversity was not significantly different between the two groups at baseline $(\mathrm{P}>0.05$; Fig. 3C-F). No significant difference in $\mathrm{d}, \mathrm{dS}$ and $\mathrm{dN}$ between the baseline and month six was identified in the NRS group $(\mathrm{P}>0.05)$.

Similar results to those for the RT region were obtained for the $\mathrm{S}$ region. The QS composition was similar to that of the RT region (data not shown). The number of QS and dominant strains exhibited no significant difference between RS and NRS at the baseline and NRS at six months, at either the nucleotide or amino acid level in the $\mathrm{S}$ region (all $\mathrm{P}>0.05$; Fig. 4). The number of QS and dominant strains in RS was not significantly different from that in NRS, at the nucleotide and the amino acid level ( $\mathrm{P}>0.05$; Fig. 4). Furthermore, the number of QS and dominant strains for NRS at the nucleotide and the amino acid level were similar between the baseline and at six months ( $\mathrm{P}>0.05$; Fig. 4). QS complexity and diversity in the S region were not significantly different between RS and NRS at the baseline and NRS at six months, at the nucleotide and the amino acid level (all P>0.05; Fig. 5). No significant difference was observed in QS complexity and diversity between RS and NRS at baseline ( $P>0.05$; Fig. 5). In the NRS group, the QS complexity and diversity did not significantly differ between baseline and six months $(\mathrm{P}>0.05)$.

Mutations within the $H B V R T$ and $S$ region. Mutated residues and mutation frequencies at different locations of HBV RT in clones of the RS and NRS group are summarized in Table II. Sequence analysis revealed that almost all clones had rtM204V/I resistance mutations prior to LAM/ADV combination rescue treatment, and the frequency of this mutation was not significantly different between the RS and NRS [167/173 (96.5\%) vs. $221 / 223$ (99.1\%), $\mathrm{P}=0.069$ ]. However, in NRS, the frequency of this mutation at baseline was higher than that 
Table I. Clinical characteristics of the RS and NRS groups.

\begin{tabular}{lccrr}
\hline Characteristic & RS $(\mathrm{n}=7)$ & NRS $(\mathrm{n}=9)$ & $\chi^{2} /$ Z-value & P-value \\
\hline Sex (M/F) & $7 / 0$ & $8 / 1$ & $1.202^{\mathrm{a}}$ & 0.273 \\
Age (years) & $35(27-48)$ & $33(25-48)$ & $-0.742^{\mathrm{b}}$ & 0.458 \\
Drug resistance to LAM (months) & $18(12-84)$ & $12(7-36)$ & $-1.456^{\mathrm{b}}$ & 0.145 \\
YMDD mutation pattern (YVDD/YIDD) & $3 / 4$ & $4 / 5$ & $0.004^{\mathrm{a}}$ & 0.949 \\
HBeAg status (+/-) & $4 / 3$ & $8 / 1$ & $2.155^{\mathrm{a}}$ & 0.142 \\
HBV genotype (B/C) & $3 / 4$ & $4 / 5$ & $0.004^{\mathrm{a}}$ & 0.949 \\
ALT (U/l) & & & & \\
Baseline & $148(61-1439)$ & $96(22-856)$ & $-1.429^{\mathrm{b}}$ & 0.153 \\
Month 3 & $30(21-120)$ & $45(29-88)$ & $-0.477^{\mathrm{b}}$ & 0.633 \\
Month 6 & $32(12-86)$ & $44(19-141)$ & $-0.370^{\mathrm{b}}$ & 0.711 \\
AST (U/l) & & & & \\
Baseline & $70(40-755)$ & $57(20-399)$ & $-1.538^{\mathrm{b}}$ & 0.124 \\
Month 3 & $30(21-56)$ & $31(22-52)$ & $-0.477^{\mathrm{b}}$ & 0.633 \\
Month 6 & $26(21-61)$ & $29(16-53)$ & $-0.106^{\mathrm{b}}$ & 0.916 \\
HBV DNA (lg copies/ml) & & & & \\
Baseline & $5.85(3.69-6.60)$ & $6.85(4.47-8.61)$ & $-1.217^{\mathrm{b}}$ & 0.223 \\
Month 3 & $<3.00(<3.00-4.52)$ & $4.20(3.00-6.79)$ & $-2.376^{\mathrm{b}}$ & 0.018 \\
Month 6 & All <3.00 & $4.23(3.06-8.12)$ & $-3.481^{\mathrm{b}}$ & $<0.001$ \\
\hline
\end{tabular}

${ }^{a} \mathrm{Chi}$-square test, count data are expressed as the number of cases; ${ }^{b} \mathrm{Mann}$-Whitney $\mathrm{U}$ test. Values are expressed as the median (range) or $\mathrm{n}$. NRS, no response; M, male; F, female; YMDD, tyrosine-methionine-aspartate-aspartate; YVDD, tyrosine-valine-aspartic-aspartic; YIDD, tyrosine-isoleucine-aspartic-aspartic; HBeAg, hepatitis B e antigen; ALT, alanine aminotransferase; AST, aspartate aminotransferase; HBV, hepatitis B virus.

A

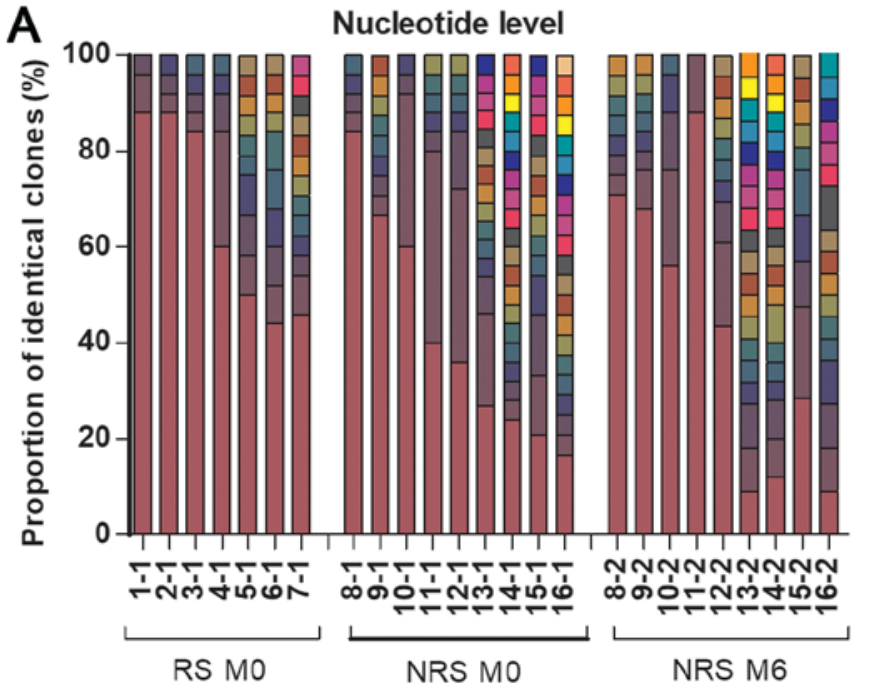

B

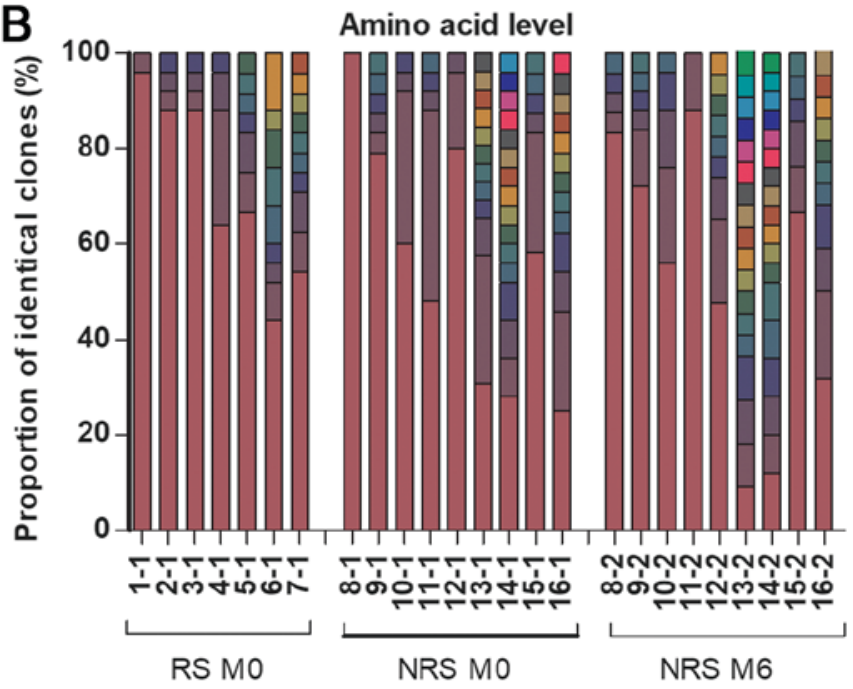

Figure 1. QS composition within the reverse transcription region of hepatitis B virus during LAM/adefovir combination rescue therapy against LAM resistance. The vertical bars represent the number and proportion of viral QS in each sample. Each color represents one specific QS. (A) QS composition at the nucleotide level and (B) QS composition at the amino acid level at M0 and M6. QS, quasispecies; LAM, lamivudine; NRS, non-responders; M0, baseline; M6, 6 months post-treatment.

at six months of combination treatment [221/223 (99.1\%) vs. 190/212 (89.6\%), P<0.001].

Prior to combination treatment, the rtA181V mutation was identified in one patient in the RS group (two in 24 clones), and no ADV resistance mutation (rtN236T) was detected. Common and frequent mutations identified in the cohort of the present study included $\mathrm{rtL80V} / \mathrm{I}, \mathrm{rtV} 84 \mathrm{M}, \mathrm{rtL} 91 \mathrm{I}$, rtN118H/D/T, rtT128A, rtL180M, rtT184L/S/A, rtV191I, $\mathrm{rtS} 202 \mathrm{G}, \mathrm{rtV} 207 \mathrm{I} / \mathrm{M}, \mathrm{rtS} 213 \mathrm{~T}, \mathrm{rtQ} 215 \mathrm{P} / \mathrm{S} / \mathrm{H}, \mathrm{rtL} 229 \mathrm{~V} / \mathrm{M} / \mathrm{W} / \mathrm{F}$, $\mathrm{rtS} 256 \mathrm{G} / \mathrm{C}$, and rtN337H/T, as presented in Table II. In addition, a stop codon mutation at site 284 was identified in one patient in the RS group (4 in 25 clones). 

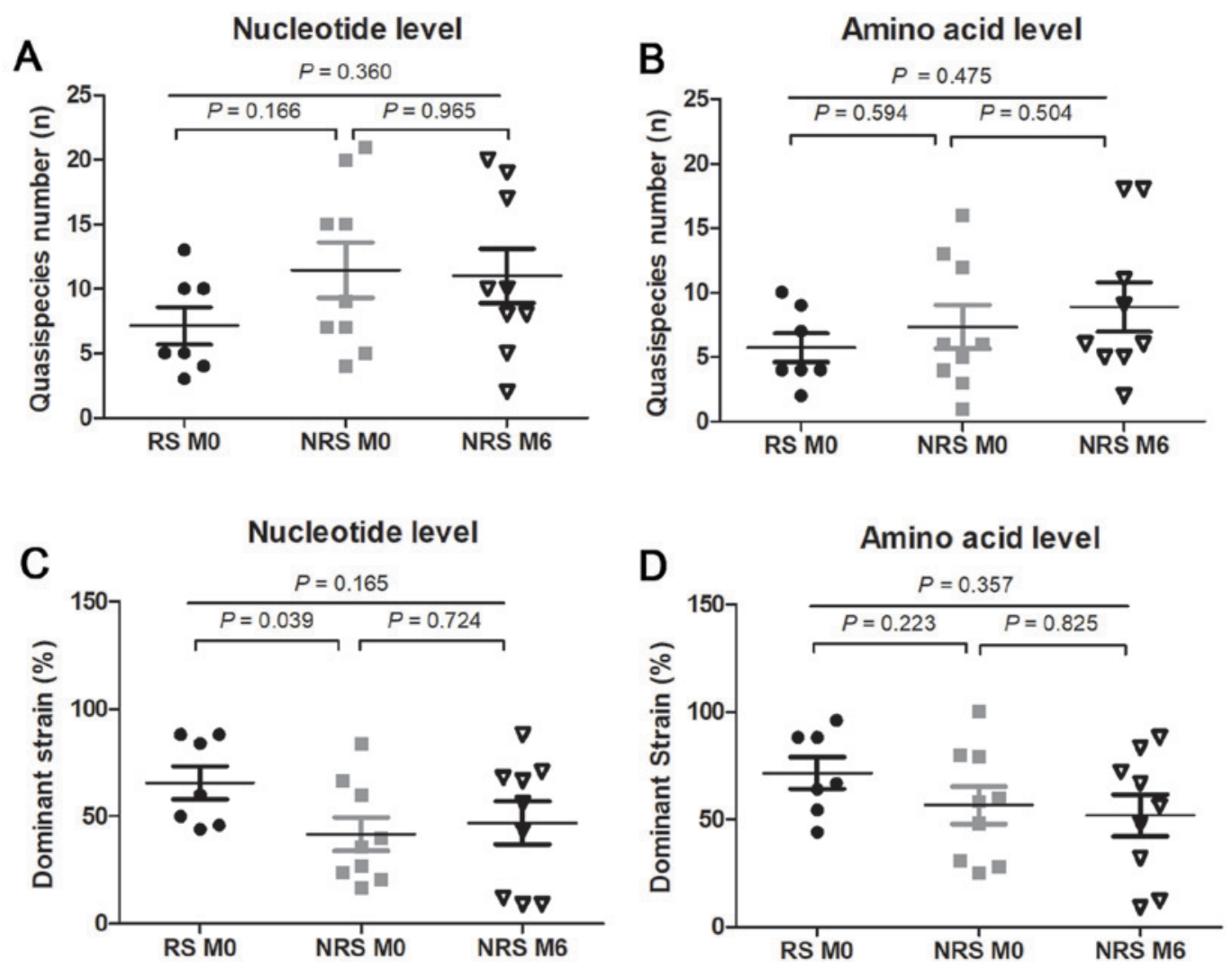

Figure 2. QS distribution within the reverse transcription region of hepatitis B virus during LAM/adefovir combination rescue therapy against LAM resistance. (A and B) Number of QS at (A) the nucleotide level and (B) the amino acid level at M0 and M6. (C and D) Frequency of dominant strains at (C) the nucleotide level and (D) the amino acid level at M0 and M6. The horizontal lines indicate mean \pm standard error of mean in every group and each point represents the number of QS in each patient. QS, quasispecies; LAM, lamivudine; NRS, non-responders; M0, baseline; M6, 6 months post-treatment.
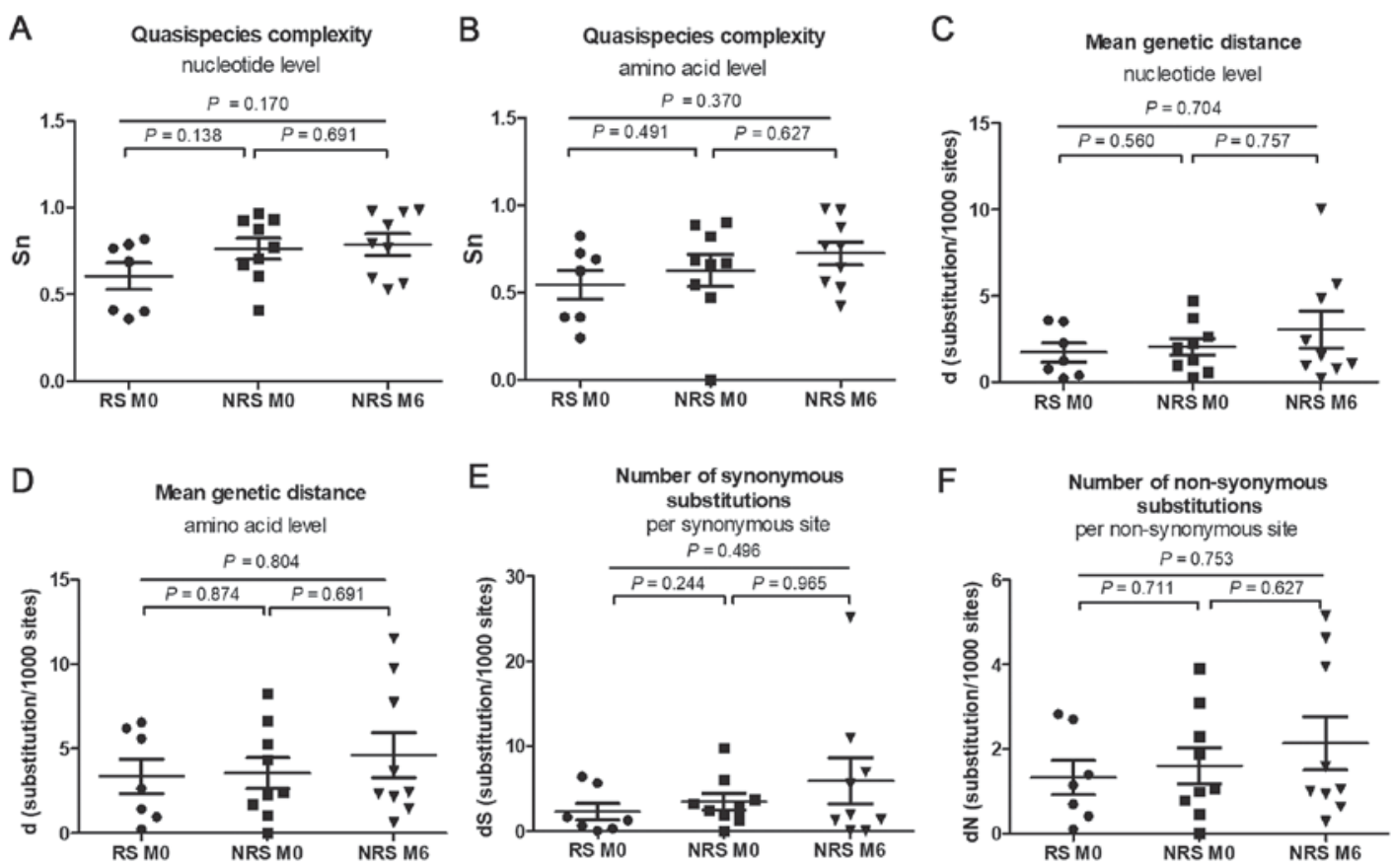

Figure 3. QS complexity and diversity in the reverse transcription region of hepatitis B virus during lamivudine/adefovir combination rescue therapy. (A and B) QS complexity at (A) the nucleotide level and (B) the amino acid level at M0 and M6; (C and D) d at (C) the nucleotide level and (D) the amino acid level at M0 and M6. (E and F) Number of (E) dS and (F) dN at M0 and M6. The horizontal lines indicate mean \pm standard error of mean in every group and each point represents the number of QS in each patient. NRS, non-response; Sn, Shannon entropy; d, mean genetic distance; dS, number of synonymous substitutions per synonymous site; dN, number of non-synonymous substitutions per non-synonymous site; QS, quasispecies; NRS, non-responders; M0, baseline; M6, 6 months post-treatment. 
A
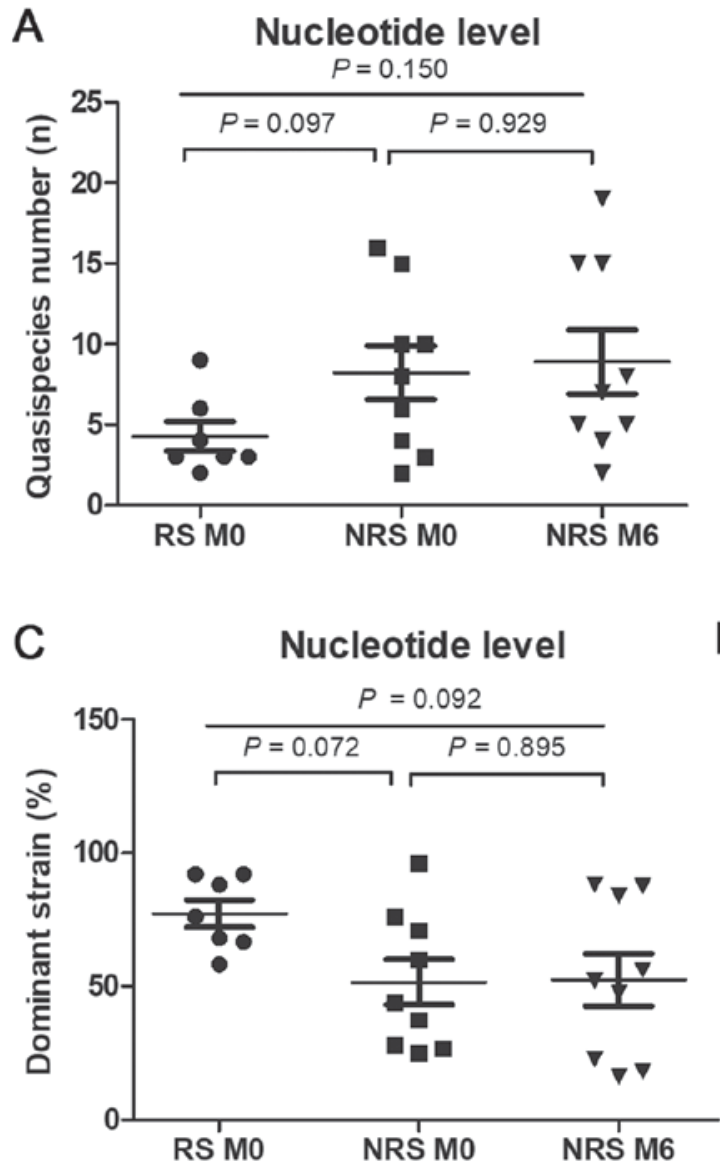

B
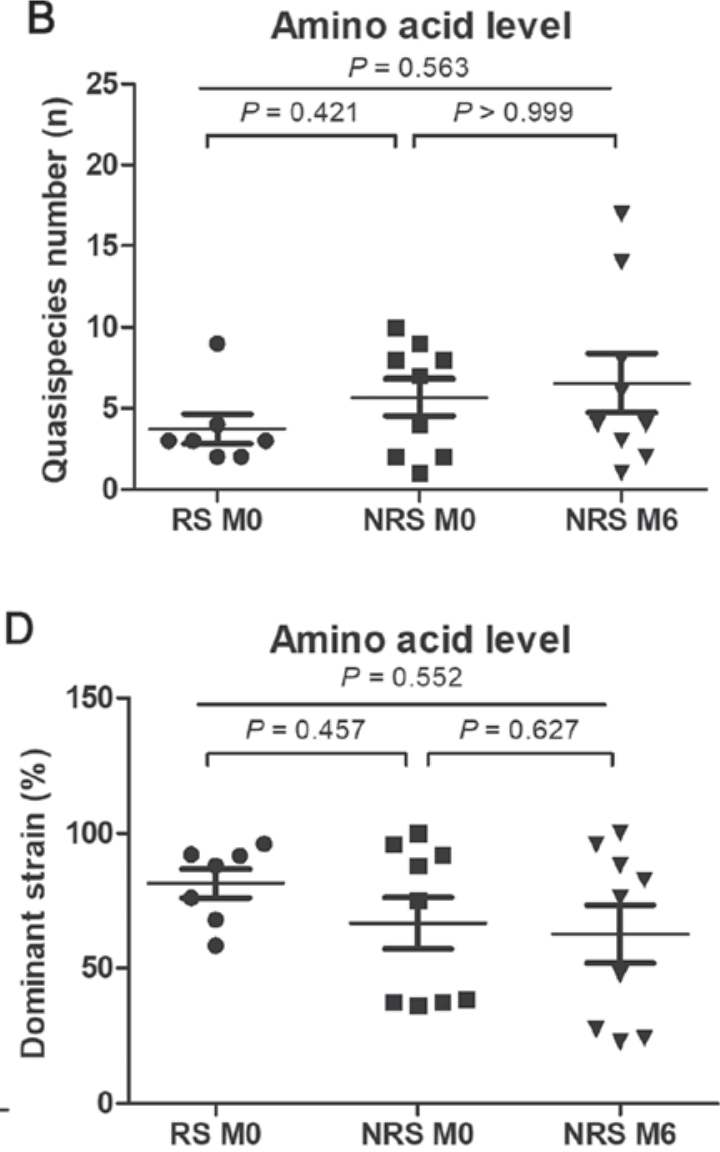

Figure 4. QS distribution in the S region of hepatitis B virus during lamivudine/adefovir combination rescue therapy. QS number at (A) the nucleotide level and (B) the amino acid level at M0 and M6. Frequency of dominant strains at (C) the nucleotide level and (D) at the amino acid level at M0 and M6. The horizontal lines indicate mean \pm standard error of mean in every group and each point represents the number of QS in each patient. QS, quasispecies; NRS, non-responders; M0, baseline; M6, 6 months post-treatment.

In the present study, the most prevalent mutations were those in the S region (sP120Q, sQ129R, sT131I, sM133I, sG145R, sY161F/H, sI195M/T, sW196S/L, sW199C/L and sM213I/T; Table III). Furthermore, three out of five stop codons in the $\mathrm{S}$ region (sS34*, sW74*, sW172*, sW182*, sW196*) were identified in the RT region; the stop codons have been associated with NAs resistance, also affected the HBsAg reading frame (rtA181T/sW172*, rtV191I/sW182* and rtM204I/sW196*).

Phylogenetic analysis. A phylogenetic tree was constructed with the maximum likelihood algorithm by aligning the HBV RT and S regions. To keep the phylogenetic tree concise, identical sequences were discarded and all QS from a patient were retained. As expected, the sequences from individual patients clustered together. While it was not possible to accurately calculate the mean branch lengths for the RS and NRS, they appeared similar (data not shown).

\section{Discussion}

Despite the availability of first-line NA therapy with a high resistance gene barrier, LAM has been widely used in China for CHB treatment (25). As a result, a large number of LAM-resistant patients have emerged, and NA resistance remains a serious problem in China (25). As a rescue treatment for LAM-resistant patients, in addition to TDF, LAM/ADV combination treatment is provided to a large number of patients due to economic reasons and availability (26). In vivo and in vitro studies have suggested that ADV is effective in patients with LAM resistance arising from YMDD mutation (5-7). The present study indicated that LAM/ADV combination treatment suppresses viral replication in certain LAM-resistant CHB patients with YMDD mutation within six months. However, 9 patients had a poor response at six months and 2 even experienced a virological breakthrough. The reason for the poor response to LAM/ADV combination treatment in cases with LAM resistance had remained elusive and required to be investigated. Earlier studies reported that HBV DNA levels are correlated with anti-viral efficacy. According to the Roadmap Concept (report of an international workshop), HBV DNA levels at week 24 are an important indicator for anti-viral efficacy and drug management (27). In the present study, patients were divided into two groups based on their virological response to combined ADV treatment at six months. No significant differences in age, sex, drug resistance to LAM, YMDD pattern, HBV genotype, ALT levels and HBeAg status were identified between these groups. HBV DNA levels at month three were revealed to be better at predicting the response to treatment for combination treatment than that at month six. In NRS, HBV DNA decreased significantly in 

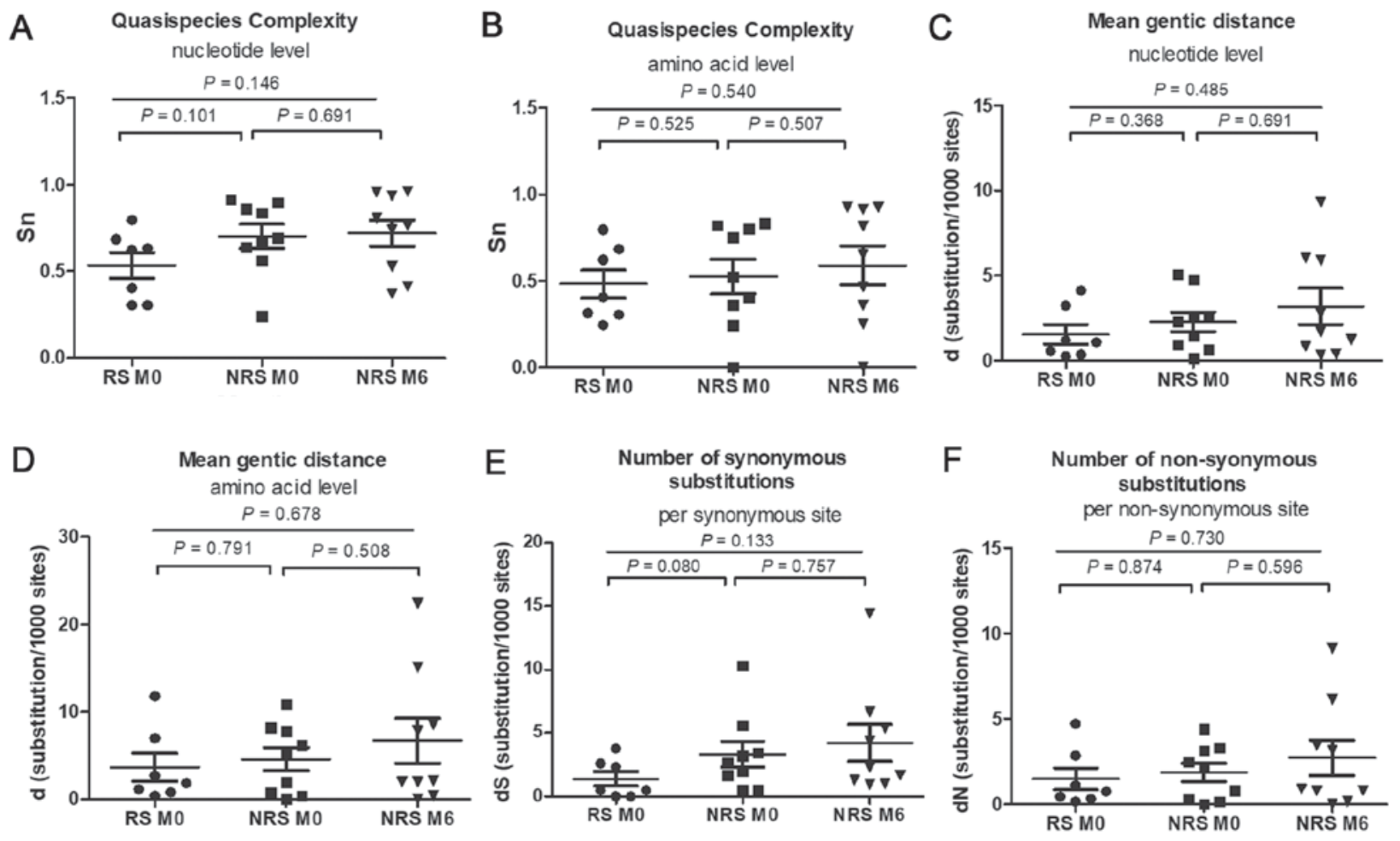

Figure 5. QS complexity and diversity in the S region of hepatitis B virus during lamivudine/adefovir combination rescue therapy. (A and B) QS complexity at (A) the nucleotide level and (B) the amino acid level at M0 and M6; (C and D) d at (C) the nucleotide level and (D) the amino acid level at M0 and M6. (E and F) Number of (E) dS and (F) dN at M0 and M6. The horizontal lines indicate mean \pm standard error of mean in every group and each point represents the number of QS in each patient. NRS, non-response; Sn, Shannon entropy; d, mean genetic distance; dS, number of synonymous substitutions per synonymous site; dN, number of non-synonymous substitutions per non-synonymous site; QS, quasispecies; NRS, non-responders; M0, baseline; M6, 6 months post-treatment.

the first three months and then plateaued. It remains elusive whether viral QS are associated with the efficacy of combination therapy. Since the RT region of HBV polymerase is the target of NAs and the $\mathrm{S}$ region overlaps with the RT region, the dynamic changes of HBV QS within the RT and S regions were investigated during LAM/ADV combination treatment to study their effects on anti-viral efficacy and drug resistance.

Most of the previous studies investigating this matter suggested that HBV QS heterogeneity in the RT and/or $\mathrm{S}$ regions may be a predictor of the anti-viral efficacy of NAs (13-15,28-30). In the present study, however, the complexity and diversity of HBV QS, whether in the RT or S region, were identified to be comparable between RS and NRS at baseline, suggesting that the QS characteristics of patients with CHB at baseline were not associated with the virological response in this cohort of patients. This result echoed those from previous studies on patients with CHB receiving NAs therapy. Chen et al (13) and Liu et al (14) investigated the HBV QS heterogeneity at baseline and identified no association with the response to NA treatment. Other studies obtained opposite results. For instance, a study by Han et al (29) using the massively parallel ultra-deep DNA pyrosequencing method suggested that the HBV QS heterogeneity at baseline is a predictor for the efficacy of LAM. In the present study, no statistically significant difference in QS heterogeneity, in either RT or the S region, was identified between the baseline and six months of treatment in NRS. This was also in line with the baseline results of a study by Lavocat et al (31), which obtained no significant difference at the baseline in QS complexity or diversity between treatment groups of patients with incomplete ADV response receiving TDF monotherapy or emtricitabine in combination. The QS complexity increased at week 12 , and the complexity and diversity decreased at week 48 in the two treatment groups (31). Whether HBV QS heterogeneity in the present cohort had a trend similar to that reported by Lavocat et al (31), which exhibited an early rise followed by a decline, has not been explored in the present study. The present study also indicated that the QS composition of RS was not significantly different from that of the NRS at baseline. Although the number of RT region dominant strains at the nucleotide level in the RS group was relatively higher than that in the NRS at baseline, the number of QS in RS was not significantly higher than that in NRS. Furthermore, analysis of the phylogenetic tree indicated that, regardless of the presence of LAM resistance, at six months after combination treatment with $\mathrm{ADV}, \mathrm{QS}$ components and complexity were not significantly changed. Therefore, the baseline QS had no significant predictive value regarding the efficacy of LAM/ADV combination therapy regarding YMDD mutant-associated LAM resistance. In the present study, a YMDD mutation was detected in all patients, and the Y-valine (V)DD and Y-isoleucine (I)DD mutation rates were also similar. During LAM/ADV combination rescue therapy, although the frequency of YMDD mutation declined, it did not disappear in NRS after six months of treatment. In a previous study, Ijaz et al (32) indicated that no reversion to wild-type 
Table II. Mutation residues and frequencies at positions within the RT region of hepatitis B virus for common antiviral drug-associated resistance variants.

\begin{tabular}{|c|c|c|c|c|c|c|}
\hline \multirow[b]{2}{*}{ RT region mutations } & \multicolumn{2}{|c|}{$\begin{array}{c}\text { Frequency } \\
\text { of mutations by } \\
\text { number of clones }(\%)^{\mathrm{a}}\end{array}$} & \multirow[b]{2}{*}{ P-value } & \multicolumn{2}{|c|}{$\begin{array}{c}\text { Frequency } \\
\text { of mutations by } \\
\text { number of samples }(\%)^{\mathrm{b}}\end{array}$} & \multirow[b]{2}{*}{ P-value } \\
\hline & Baseline & Month 6 & & Baseline & Month 6 & \\
\hline \multicolumn{7}{|c|}{ Lamivudine-associated resistance } \\
\hline $\mathrm{L} 80 \mathrm{I} / \mathrm{V}$ & & & $0.957^{\mathrm{c}}$ & 28.6 & & $0.276^{\mathrm{c}}$ \\
\hline RS & 28.9 & & & & & \\
\hline NRS & 29.1 & 11.3 & $<0.001^{\mathrm{d}}$ & 55.6 & 33.3 & $0.341^{\mathrm{d}}$ \\
\hline $\mathrm{L} 82 \mathrm{M} / \mathrm{F}$ & & & 0.129 & & & 0.112 \\
\hline RS & 0 & & & 0 & & \\
\hline NRS & 0.9 & 0 & 0.102 & 22.2 & 0 & 0.082 \\
\hline L91I & & & $<0.001$ & & & 0.055 \\
\hline RS & 26.6 & & & 28.6 & & \\
\hline NRS & 0 & 0.9 & 0.089 & 0 & 11.1 & 0.229 \\
\hline $\mathrm{T} 128 \mathrm{~A}$ & & & $<0.001$ & & & 0.375 \\
\hline $\mathrm{RS}$ & 28.3 & & & 28.6 & & \\
\hline NRS & 11.2 & 11.8 & 0.849 & 11.1 & 11.1 & 1.000 \\
\hline N139D & & & 0.189 & & & 0.187 \\
\hline RS & 0.6 & & & 14.3 & & \\
\hline NRS & 0 & 0 & 1.000 & 0 & 0 & 1.000 \\
\hline R153Q & & & 0.129 & & & 0.273 \\
\hline RS & 0 & & & 0 & & \\
\hline NRS & 0.9 & 0 & 0.102 & 11.1 & 0 & 0.229 \\
\hline L180M & & & 0.038 & & & 0.377 \\
\hline RS & 39.3 & & & 57.1 & & \\
\hline NRS & 49.8 & 57.1 & 0.127 & 77.8 & 77.8 & 1.000 \\
\hline $\mathrm{M} 204 \mathrm{~V}$ & & & 0.453 & & & 0.614 \\
\hline RS & 39.3 & & & 42.9 & & \\
\hline NRS & 43.0 & 45.3 & 0.639 & 55.6 & 55.6 & 1.000 \\
\hline M204I & & & 0.816 & & & 0.949 \\
\hline RS & 57.2 & & & 57.1 & & \\
\hline NRS & 56.1 & 44.3 & 0.015 & 55.6 & 55.6 & 1.000 \\
\hline M204I/V & & & 0.069 & & & 1.000 \\
\hline $\mathrm{RS}$ & 96.5 & & & 100 & & \\
\hline NRS & 99.1 & 89.6 & $<0.001$ & 100 & 100.0 & 1.000 \\
\hline $\mathrm{L} 229 \mathrm{~V} / \mathrm{W} / \mathrm{M} / \mathrm{F}$ & & & $<0.001$ & & & 0.614 \\
\hline $\mathrm{RS}$ & 36.4 & & & 57.1 & & \\
\hline NRS & 19.7 & 17.0 & 0.459 & 44.4 & 44.4 & 1.000 \\
\hline $\mathrm{S} 256 \mathrm{G} / \mathrm{C}$ & & & 0.944 & & & 0.849 \\
\hline $\mathrm{RS}$ & 11.0 & & & 14.3 & & \\
\hline NRS & 10.8 & 10.8 & 0.977 & 11.1 & 11.1 & 1.000 \\
\hline \multicolumn{7}{|c|}{ Adefovir-associated resistance } \\
\hline V84M & & & $<0.001$ & & & 0.187 \\
\hline $\mathrm{RS}$ & 14.5 & & & 14.3 & & \\
\hline NRS & 0.0 & 8.5 & $<0.001$ & 0 & 11.1 & 0.229 \\
\hline $\mathrm{N} 118 \mathrm{H} / \mathrm{D} / \mathrm{T}$ & & & 0.411 & & & 0.684 \\
\hline $\mathrm{RS}$ & 14.5 & & & 14.3 & & \\
\hline NRS & 11.7 & 11.3 & 0.912 & 22.2 & 11.1 & 0.524 \\
\hline $\mathrm{A} 181 \mathrm{~T}$ & & & 0.068 & & & 0.187 \\
\hline $\mathrm{RS}$ & 1.2 & & & 14.3 & & \\
\hline NRS & 0 & 0 & 1.000 & 0 & 0 & 1.000 \\
\hline
\end{tabular}


Table II. Continued.

\begin{tabular}{|c|c|c|c|c|c|c|}
\hline \multirow[b]{2}{*}{ RT region mutations } & \multicolumn{2}{|c|}{$\begin{array}{c}\text { Frequency } \\
\text { of mutations by } \\
\text { number of clones }(\%)^{\mathrm{a}}\end{array}$} & \multirow[b]{2}{*}{ P-value } & \multicolumn{2}{|c|}{$\begin{array}{c}\text { Frequency } \\
\text { of mutations by } \\
\text { number of samples }(\%)^{\mathrm{b}}\end{array}$} & \multirow[b]{2}{*}{ P-value } \\
\hline & Baseline & Month 6 & & Baseline & Month 6 & \\
\hline S213T & & & 0.004 & & & 0.273 \\
\hline RS & 0.0 & & & 0 & & \\
\hline NRS & 3.1 & 1.4 & 0.223 & 11.1 & 11.1 & 1.000 \\
\hline $\mathrm{I} 233 \mathrm{~L}$ & & & 0.283 & & & 0.273 \\
\hline RS & 0.0 & & & 0 & & \\
\hline NRS & 0.4 & 0 & 0.247 & 11.1 & 0 & 0.229 \\
\hline $\mathrm{N} 236 \mathrm{~T}$ & & & 1.000 & & & 1.000 \\
\hline RS & 0 & & & 0 & & \\
\hline NRS & 0 & 0 & 1.000 & 0 & 0 & 1.000 \\
\hline $\mathrm{P} 237 \mathrm{~T}$ & & & 1.000 & & & 1.000 \\
\hline $\mathrm{RS}$ & 0.0 & & & 0 & & \\
\hline NRS & 0.0 & 0.5 & 0.230 & 0 & 11.1 & 0.229 \\
\hline \multicolumn{7}{|c|}{$\begin{array}{l}\text { Lamivudine+adefovir-associated } \\
\text { resistance }\end{array}$} \\
\hline rtV191I & & & $<0.001$ & & & 0.375 \\
\hline RS & 15.0 & & & 28.6 & & \\
\hline NRS & 0.9 & 0.5 & 0.588 & 11.1 & 11.1 & 1.000 \\
\hline V207I/M & & & 0.004 & & & 0.273 \\
\hline RS & 0 & & & 0 & & \\
\hline NRS & 3.1 & 2.8 & 0.850 & 11.1 & 22.2 & 0.524 \\
\hline $\mathrm{Q} 215 \mathrm{P} / \mathrm{S} / \mathrm{H}$ & & & $<0.001$ & & & 0.187 \\
\hline RS & 14.5 & & & 14.3 & & \\
\hline NRS & 0 & 0.0 & 1.000 & 0 & 0 & 1.000 \\
\hline \multicolumn{7}{|c|}{ Entecavir-associated resistance } \\
\hline rtI169T & & & 0.129 & & & 0.273 \\
\hline RS & 0 & & & 0 & & \\
\hline NRS & 0.9 & 0.9 & 0.959 & 11.1 & 11.1 & 1.000 \\
\hline $\mathrm{T} 184 \mathrm{~L} / \mathrm{S} / \mathrm{A}$ & & & $<0.001$ & & & 0.112 \\
\hline $\mathrm{RS}$ & 0 & & & 0 & & \\
\hline NRS & 11.7 & 15.6 & 0.234 & 22.2 & 22.2 & 1.000 \\
\hline S202G & & & $<0.001$ & & & 0.273 \\
\hline $\mathrm{RS}$ & 0 & & & 0 & & \\
\hline NRS & 9.4 & 7.5 & 0.485 & 11.1 & 11.1 & 1.000 \\
\hline \multicolumn{7}{|c|}{$\begin{array}{l}\text { Other possible associated } \\
\text { resistance }\end{array}$} \\
\hline M271L & & & 0.129 & & & 0.273 \\
\hline RS & 0 & & & 0 & & \\
\hline NRS & 0.9 & 0 & 0.102 & 11.1 & 0 & 0.229 \\
\hline $\mathrm{W} 284^{\mathrm{e}}$ & & & 0.100 & & & 0.187 \\
\hline $\mathrm{RS}$ & 2.3 & & & 14.3 & & \\
\hline NRS & 0 & 0 & 1.000 & 0 & 0 & 1.000 \\
\hline $\mathrm{N} 337 \mathrm{H} / \mathrm{T}$ & & & $<0.001$ & & & 0.684 \\
\hline $\mathrm{RS}$ & 14.5 & & & 14.3 & & \\
\hline NRS & 0.9 & 1.4 & 0.611 & 22.2 & 22.2 & 1.000 \\
\hline
\end{tabular}


Table III. Mutation residue frequencies at different positions of the HBV S region.

\begin{tabular}{|c|c|c|c|c|c|c|c|}
\hline \multirow[b]{2}{*}{$S$ region mutations } & \multirow[b]{2}{*}{ Response } & \multicolumn{2}{|c|}{$\begin{array}{c}\text { Frequency of } \\
\text { clones mutations }(\%)^{\mathrm{a}}\end{array}$} & \multirow[b]{2}{*}{ P-value } & \multicolumn{2}{|c|}{$\begin{array}{c}\text { Frequency } \\
\text { of individuals } \\
\text { mutations }(\%)^{\mathrm{b}}\end{array}$} & \multirow[b]{2}{*}{ P-value } \\
\hline & & Baseline & Month 6 & & Baseline & Month 6 & \\
\hline \multicolumn{8}{|l|}{ Stop codon mutation } \\
\hline \multirow[t]{2}{*}{$\mathrm{S} 34 * \mathrm{e}$} & RS & 0 & & $0.283^{c}$ & 0 & & $0.273^{\mathrm{c}}$ \\
\hline & NRS & 0.4 & 0 & $0.247^{\mathrm{d}}$ & 11.1 & 0 & $0.229^{\mathrm{d}}$ \\
\hline \multirow[t]{2}{*}{$\mathrm{W} 74 * \mathrm{e}$} & $\mathrm{RS}$ & 0 & & $0.283^{\mathrm{c}}$ & 0 & & $0.273^{\mathrm{c}}$ \\
\hline & NRS & 0.4 & 0 & $0.247^{\mathrm{d}}$ & 11.1 & 0 & $0.229^{d}$ \\
\hline \multirow[t]{2}{*}{$\mathrm{W} 172 * \mathrm{e}$} & RS & 1.2 & & $0.068^{\mathrm{c}}$ & 14.3 & & $0.187^{\mathrm{c}}$ \\
\hline & NRS & 0 & 0 & $1.000^{\mathrm{d}}$ & 0 & 0 & $1.000^{\mathrm{d}}$ \\
\hline \multirow[t]{2}{*}{$\mathrm{W} 182 * \mathrm{e}$} & $\mathrm{RS}$ & 15.0 & & $<0.001^{\mathrm{c}}$ & 14.3 & & $0.375^{\mathrm{c}}$ \\
\hline & NRS & 0.9 & 0.5 & $0.588^{\mathrm{d}}$ & 11.1 & 11.1 & $1.000^{\mathrm{d}}$ \\
\hline \multirow[t]{2}{*}{ W196*e } & $\mathrm{RS}$ & 14.5 & & $<0.001^{\mathrm{c}}$ & 14.3 & & $0.849^{c}$ \\
\hline & NRS & 0.4 & 5.7 & $0.001^{\mathrm{d}}$ & 11.1 & 11.1 & $1.000^{\mathrm{d}}$ \\
\hline \multicolumn{8}{|l|}{ Other mutations } \\
\hline \multirow[t]{2}{*}{ P120Q } & $\mathrm{RS}$ & 0 & & $1.000^{\mathrm{c}}$ & 0 & & $1.000^{\mathrm{c}}$ \\
\hline & NRS & 0 & 0.5 & $0.230^{\mathrm{d}}$ & 0 & 11.1 & $0.229^{d}$ \\
\hline \multirow[t]{2}{*}{ Q129R } & $\mathrm{RS}$ & 11.0 & & $<0.001^{\mathrm{c}}$ & 14.3 & & $0.187^{\mathrm{c}}$ \\
\hline & NRS & 0 & 0 & $1.000^{\mathrm{d}}$ & 0 & 0 & $1.000^{\mathrm{d}}$ \\
\hline \multirow[t]{2}{*}{$\mathrm{T} 131 \mathrm{I}$} & $\mathrm{RS}$ & 9.2 & & $<0.001^{\mathrm{c}}$ & 14.3 & & $0.187^{\mathrm{c}}$ \\
\hline & NRS & 0 & 0 & $1.000^{\mathrm{d}}$ & 0 & 0 & $1.000^{\mathrm{d}}$ \\
\hline \multirow[t]{2}{*}{ M133I } & $\mathrm{RS}$ & 0 & & $1.000^{\mathrm{c}}$ & 0 & & $1.000^{\mathrm{c}}$ \\
\hline & NRS & 0 & 0.5 & $0.230^{\mathrm{d}}$ & 0 & 11.1 & $0.229^{d}$ \\
\hline \multirow[t]{2}{*}{ G145R } & $\mathrm{RS}$ & 0 & & $0.129^{c}$ & 0 & & $0.273^{c}$ \\
\hline & NRS & 0.9 & 0 & $0.102^{\mathrm{d}}$ & 11.1 & 0 & $0.229^{d}$ \\
\hline \multirow[t]{2}{*}{$\mathrm{Y} 161 \mathrm{~F} / \mathrm{H}$} & $\mathrm{RS}$ & 0 & & $<0.001^{\mathrm{c}}$ & 0 & & $0.112^{c}$ \\
\hline & NRS & 12.6 & 10.4 & $0.476^{\mathrm{d}}$ & 22.2 & 11.1 & $0.524^{\mathrm{d}}$ \\
\hline \multirow[t]{2}{*}{$\mathrm{I} 195 \mathrm{M} / \mathrm{T}$} & $\mathrm{RS}$ & 53.8 & & $0.034^{\mathrm{c}}$ & 57.1 & & $0.949^{c}$ \\
\hline & NRS & 43.0 & 45.3 & $0.639^{d}$ & 55.6 & 55.6 & $1.000^{\mathrm{d}}$ \\
\hline \multirow[t]{2}{*}{ W196S/L } & $\mathrm{RS}$ & 42.8 & & $0.030^{c}$ & 57.1 & & $0.949^{c}$ \\
\hline & NRS & 56.1 & 38.7 & $0.002^{\mathrm{d}}$ & 55.6 & 55.6 & $1.000^{\mathrm{d}}$ \\
\hline \multirow[t]{2}{*}{ W199C/L } & $\mathrm{RS}$ & 0.6 & & $0.053^{\mathrm{c}}$ & 14.3 & & $0.849^{c}$ \\
\hline & NRS & 3.1 & 1.4 & $0.223^{\mathrm{d}}$ & 11.1 & 11.1 & $1.000^{\mathrm{d}}$ \\
\hline \multirow[t]{2}{*}{ M213I/T } & RS & 18.5 & & $<0.001^{\mathrm{c}}$ & 28.6 & & $0.513^{c}$ \\
\hline & NRS & 43.5 & 37.3 & $0.185^{\mathrm{d}}$ & 44.4 & 44.4 & $1.000^{\mathrm{d}}$ \\
\hline
\end{tabular}

RS, response; NRS, nonresponse; ${ }^{a}$ number of clones with mutation(s) in the group/total number of clones from the group; ${ }^{\text {bnumber of samples }}$ with mutations in the group/total number of samples from the group, ${ }^{\mathrm{c}} \mathrm{P}-\mathrm{value}$ for comparison between the RS and the NRS group at baseline, ${ }^{\mathrm{d}} \mathrm{P}$-value for baseline and 6 months post-treatment in the NRS group; ${ }^{\mathrm{e}} \mathrm{Stop}$ codon mutation.

HBV occurred in patients with LAM-resistant HBV receiving LAM/ADV combination therapy. In addition to the emergence of the YMDD mutation, other LAM-associated mutations were also detected in the clonal analysis, e.g. rtA181T was detected in one patient in the RS group. The rtA181T mutation has been suggested as an atypical mutation associated with LAM and ADV resistance (33). This patient developed a virological breakthrough during the follow-up (data not shown). The ADV resistance- associated rtN236T mutation was not detected at all in the present study. Other mutations, including rtV84M,
rtN118H/D/T, rtI169T, rtT184A/L/S, rtV191I, rtV207I/M, $\mathrm{rtS} 213 \mathrm{~T}, \mathrm{rtQ} 215 \mathrm{P} / \mathrm{S} / \mathrm{H}, \mathrm{rtI} 233 \mathrm{~L}, \mathrm{rtP} 237 \mathrm{H} / \mathrm{T}$ and $\mathrm{rtS} 202 \mathrm{G}$, which have been previously reported to be associated with ADV or ETV resistance $(34,35)$, were detected at baseline or after six months of LAM/ADV treatment. In addition, the substitution mutation rtA194T, which has been associated with TDF resistance (36), was not detected. Hence, these results suggest that TDF, but not ADV or ETV, should be considered for the treatment of patients with LAM resistance. In addition to these well-documented major and compensatory mutations, 
2 more mutations (rtS256G/C and $\mathrm{rtM} 337 \mathrm{H} / \mathrm{T}$ ) were detected at a high rate. Furthermore, rtW284* was detected in one RS patient (4 of 25 clones) at baseline. The significance of these mutations requires to be investigated in follow-up studies. However, in the present study, no definite association between certain mutations and a patient's response to combination therapy was established.

Since the polymerase gene overlaps with the $\mathrm{S}$ gene, a mutation in the nucleoside may result in amino acid mutations in the RT and S genes. Similar to previous studies, the present study suggested that truncation mutations (rtA181T/sW172*, rtM204I/sW196* and rtV191I/sW182*) occurred at the highest frequency $(37,38)$. Other studies have indicated that these three mutants may hamper virion secretion, leading to HBsAg protein retention and decreased serum HBV DNA levels. In the present study, most $S$ region mutations were located in the ' $a$ ' determinant and were detected in NRS rather than in RS (17). In contrast to previous studies, a number of $S$ gene mutations (e.g. sP120T and sG145R) that may be associated with LAM resistance (39), were not detected in the present study. However, the significance of these mutations has remained to be assessed in detail.

Of note, the present study had certain limitations. First, the sample size was relatively small. Furthermore, the present study only cloned HBV DNA samples obtained at baseline and six months after LAM/ADV rescue treatment. HBV DNA from other follow-up time-points were not cloned due to lack of available serum samples. In addition, the cloning strategy applied in the present study was expensive and labor-intensive, and ultra-deep pyrosequencing may be a good alternative, but cloning/sequencing is considered as the gold standard technique for assessment of viral QS (14). However, the major aim of the present study was to assess the QS of patients with drug-resistance, which is different from that of other studies on treatment-naïve patients.

In conclusion, the present study indicated that in $\mathrm{CHB}$ patients with LAM resistance, the baseline HBV QS within the RT and S regions was not significantly different between RS and NRS during rescue treatment with LAM/ADV. The baseline viral QS of HBV in patients with YMDD mutations may not predict the efficacy of combination therapy with LAM/ADV in LAM-resistant patients. In addition, no specific HBV mutant was selected during rescue treatment with LAM/ADV for LAM resistance. Finally, LAM resistance may occur in HBV variants with cross-resistance to other NAs, including Telbivudine Entecavir and ADV (when rt180 mutation occurs), so rescue treatment with TDF rather than ADV should be recommended. Future large-scale studies using samples collected prior to and after therapy with NAs are required to clarify the resistance-associated dynamics of viral QS.

\section{Acknowledgements}

Not applicable.

\section{Funding}

The current study was supported by the National Science Foundation of China (grant no. 81273142) and the Provincial Natural Science Foundation (grant no. 1608085MH162).

\section{Availability of data and materials}

The datasets used and/or analyzed during the current study are available from the corresponding author on reasonable request.

\section{Authors' contributions}

$\mathrm{ZZ}$ conceived the study, performed the literature search and edited the manuscript. CW, SY, YZ, MZ, LL and CH performed the experiments. $\mathrm{CW}, \mathrm{CH}$ and $\mathrm{ZZ}$ analyzed the data and wrote the manuscript. XL, $\mathrm{CH}$ and JL reviewed the manuscript. XL was responsible for the acquisition of funding, collection of data and general supervision of the research group. XL, JL and $\mathrm{ZZ}$ provided reagents, materials and analysis tools. $\mathrm{CW}$, $\mathrm{JL}$ and $\mathrm{ZZ}$ interpreted the data.

\section{Ethics approval and patient consent}

The study was approved by the Ethics Committee of Anhui Medical University (Hefei, China) and written informed consent was obtained from all patients.

\section{Patient consent for publication}

Not applicable.

\section{Competing interests}

The authors declare that they have no competing interests.

\section{References}

1. Ott JJ, Stevens GA, Groeger J and Wiersma ST: Global epidemiology hepatitis B virus infection: New estimates of age-specific HBsAg seroprevalence and endemicity. Vaccine 30: 2212-2219, 2012.

2. Lavanchy D: Hepatitis B virus epidemiology, disease burden, treatment, and current and emerging prevention and control measures. J Viral Hepat 11: 97-107, 2004

3. Geretti AM, Patel M, Sarfo FS, Chadwick D, Verheyen J, Fraune M, Garcia A and Phillips RO: Detection of highly prevalent hepatitis B virus coinfection among HIV-seropositive persons in Ghana. J Clin Microbiol 48: 3223-3230, 2010.

4. Lok AS, Lai CL, Leung N, Yao GB, Cui ZY, Schiff ER, Dienstag JL, Heathcote EJ, Little NR, Griffiths DA, et al: Long-term safety of lamivudine treatment in patients with chronic hepatitis B. Gastroenterology 125: 1714-1722, 2003.

5. Kim HJ, Park JH, Park DI, Cho YK, Sohn CI, Jeon WK and Kim BI: Rescue therapy for lamivudine-resistant chronic hepatitis B: Comparison between entecavir $1.0 \mathrm{mg}$ monotherapy, adefovir monotherapy and adefovir add-on lamivudine combination therapy. J Gastroenterol Hepatol 25: 1374-1380, 2010.

6. Perrillo R, Hann HW, Mutimer D, Willems B, Leung N, Lee WM, Moorat A, Gardner S, Woessner M, Bourne E, et al: Adefovir dipivoxil added to ongoing lamivudine in chronic hepatitis $\mathrm{B}$ with YMDD mutant hepatitis B virus. Gastroenterology 126: 81-90, 2004.

7. Vassiliadis TG, Giouleme O, Koumerkeridis G, Koumaras H, Tziomalos K, Patsiaoura K, Grammatikos N, Mpoumponaris A, Gkisakis D, Theodoropoulos K, et al: Adefovir plus lamivudine are more effective than adefovir alone in lamivudine-resistant $\mathrm{HBeAg}$-chronic hepatitis B patients: A 4-year study. J Gastroenterol Hepatol 25: 54-60, 2010.

8. Lee YS, Suh DJ, Lim YS, Jung SW, Kim KM, Lee HC, Chung YH, Lee YS, Yoo W and Kim SO: Increased risk of adefovir resistance in patients with lamivudine-resistant chronic hepatitis B after 48 weeks of adefovir dipivoxil monotherapy. Hepatology 43: 1385-1391, 2006. 
9. Zhou B, Dong H, He Y, Sun J, Jin W, Xie Q, Fan R, Wang M, Li R, Chen Y, et al: Composition and interactions of hepatitis $B$ virus quasispecies defined the virological response during telbivudine therapy. Sci Rep 5: 17123, 2015.

10. Domingo E and Gomez J: Quasispecies and its impact on viral hepatitis. Virus Res 127: 131-150, 2007.

11. Fan X, Mao Q, Zhou D, Lu Y, Xing J, Xu Y, Ray SC and Di Bisceglie AM: High diversity of hepatitis $\mathrm{C}$ viral quasispecies is associated with early virological response in patients undergoing antiviral therapy. Hepatology 50: 1765-1772, 2009.

12. Sherman KE, Rouster SD, Stanford S, Blackard JT, Shire N, Koziel M, Peters $M$ and Chung RT; AIDS Clinical Trials Group 5071 Study Team: Hepatitis C virus (HCV) quasispecies complexity and selection in HCV/HIV-coinfected subjects treated with interferon-based regimens. J Infect Dis 201: 712-719, 2010.

13. Chen L, Zhang Q, Yu DM, Wan MB and Zhang XX: Early changes of hepatitis B virus quasispecies during lamivudine treatment and the correlation with antiviral efficacy. J Hepatol 50: 895-905, 2009.

14. Liu F, Chen L, Yu DM, Deng L, Chen R, Jiang Y, Chen L, Huang SY, Yu JL, Gong QM and Zhang XX: Evolutionary patterns of hepatitis B virus quasispecies under different selective pressures: Correlation with antiviral efficacy. Gut 60: 1269-1277, 2011.

15. Peveling-Oberhag J, Herrmann E, Kronenberger B, Farnik H, Susser S, Sarrazin C, Zeuzem S and Hofmann WP: Dynamics of hepatitis B virus quasispecies heterogeneity and virologic response in patients receiving low-to-moderate genetic barrier nucleoside analogs. J Viral Hepat 20: 234-239, 2013.

16. Yin F, Wu Z, Fang W, Wu C, Rayner S, Han M, Deng F, Du R, Liu J, Wang M, et al: Resistant mutations and quasispecies complexity of hepatitis B virus during telbivudine treatment. J Gen Virol 96: 3302-3312, 2015.

17. Sheldon J and Soriano V: Hepatitis B virus escape mutants induced by antiviral therapy. J Antimicrob Chemother 61: 766-768, 2008

18. Chen CH, Lee CM, Tung WC, Wang JH, Hung CH, Hu TH, Wang JC, Lu SN and Changchien CS: Evolution of full-length HBV sequences in chronic hepatitis B patients with sequential lamivudine and adefovir dipivoxil resistance. J Hepatol 52: 478-485, 2010

19. Zhu H, Wang C, Zhang Y, Wei S, Li X and Zhang Z: Prediction model for sustained hepatitis $B$ e antigen seroconversion to peginterferon alfa-2a in chronic hepatitis B. J Gastroenterol Hepatol 31: 1963-1970, 2016

20. Hall TA: BioEdit: A user-friendly biological sequence alignment editor and analysis program for Windows 95/98/NT. Nucl Acids Symp Ser 41: 95-98, 1999.

21. Thompson JD, Gibson TJ, Plewniak F, Jeanmougin F and Higgins DG: The CLUSTAL X windows interface: Flexible strategies for multiple sequence alignment aided by quality analysis tools. Nucleic Acids Res 25: 4876-4882, 1997.

22. Martin D and Rybicki E: RDP: Detection of recombination amongst aligned sequences. Bioinformatics 16: 562-563, 2000.

23. Domingo E, Martin V, Perales C, Grande-Pérez A Garcia-Arriaza J and Arias A: Viruses as quasispecies: Biological implications. Curr Top Microbiol Immunol 299: 51-82, 2006.

24. Kumar S, Stecher G and Tamura K: MEGA7: Molecular evolutionary genetics analysis version 7.0 for bigger datasets. Mol Biol Evol 33: 1870-1874, 2016.

25. Zheng X, Wang J and Yang D: Antiviral therapy for chronic hepatitis B in China. Med Microbiol Immunol 204: 115-120, 2015.
26. Lee HJ, Kim SJ, Kweon YO, Park SY, Heo J, Woo HY, Hwang JS, Chung WJ, Lee CH, Kim BS, et al: Evaluating the efficacy of switching from lamivudine plus adefovir to tenofovir disoproxil fumarate monotherapy in lamivudine-resistant stable hepatitis B patients. PLoS One 13: e0190581, 2018.

27. Keeffe EB, Zeuzem S, Koff RS, Dieterich DT, Esteban-Mur R, Gane EJ, Jacobson IM, Lim SG, Naoumov N, Marcellin P, et al: Report of an international workshop: Roadmap for management of patients receiving oral therapy for chronic hepatitis B. Clin Gastroenterol Hepatol 5: 890-897, 2007.

28. Cheng Y, Guindon S, Rodrigo A and Lim SG: Increased viral quasispecies evolution in HBeAg seroconverter patients treated with oral nucleoside therapy. J Hepatol 58: 217-224, 2013.

29. Han Y, Gong L, Sheng J, Liu F, Li XH, Chen L, Yu DM, Gong QM, Hao $\mathrm{P}$ and Zhang XX: Prediction of virological response by pretreatment hepatitis $B$ virus reverse transcriptase quasispecies heterogeneity: The advantage of using next-generation sequencing. Clin Microbiol Infect 21: 797.e1-e8, 2015

30. Chen L, Gan QR, Zhang DQ, Yao LF, Lin RS, Li Q, Lin MH, Yu DM, Zhang XX and Pan C: Increased intrahepatic quasispecies heterogeneity correlates with off-treatment sustained response to nucleos $(\mathrm{t})$ ide analogues in e antigen-positive chronic hepatitis B patients. Clin Microbiol Infect 22: 201-207, 2016.

31. Lavocat F, Dény P, Pichoud C, Al Hawajri N, Kitrinos K, Borroto-Esoda K and Zoulim F: Similar evolution of hepatitis B virus quasispecies in patients with incomplete adefovir response receiving tenofovir/emtricitabine combination or tenofovir monotherapy. J Hepatol 59: 684-695, 2013.

32. Ijaz S, Arnold C, Dervisevic S, Mechurova J, Tatman N, Tedder RS and Naoumov NV: Dynamics of lamivudine-resistant hepatitis B virus during adefovir monotherapy versus lamivudine plus adefovir combination therapy. J Med Virol 80: 1160-1170, 2008.

33. Villet S, Pichoud C, Billioud G, Barraud L, Durantel S, Trépo C and Zoulim F: Impact of hepatitis B virus rtA181V/T mutants on hepatitis B treatment failure. J Hepatol 48: 747-755, 2008.

34. Lapiński TW, Pogorzelska J and Flisiak R: HBV mutations and their clinical significance. Adv Med Sci 57: 18-22, 2012.

35. Zhang ZH, Wu CC, Chen XW, Li X, Li J and Lu MJ: Genetic variation of hepatitis $B$ virus and its significance for pathogenesis. World J Gastroenterol 22: 126-144, 2016.

36. Sheldon J, Camino N, Rodés B, Bartholomeusz A, Kuiper M, Tacke F, Núñez M, Mauss S, Lutz T, Klausen G, et al: Selection of hepatitis B virus polymerase mutations in HIV-coinfected patients treated with tenofovir. Antivir Ther 10: 727-734, 2005.

37. Coppola N, Onorato L, Minichini C, Di Caprio G, Starace M, Sagnelli C and Sagnelli E: Clinical significance of hepatitis B surface antigen mutants. World J Hepatol 7: 2729-2739, 2015

38. Wang ML and Tang H: Nucleos(t)ide analogues causes HBV S gene mutations and carcinogenesis. Hepatobiliary Pancreat Dis Int 15: 579-586, 2016.

39. Amini-Bavil-Olyaee S, Vucur M, Luedde T, Trautwein C and Tacke F: Differential impact of immune escape mutations G145R and P120T on the replication of lamivudine-resistant hepatitis B virus e antigen-positive and -negative strains. J Virol 84: 1026-1033, 2010.

This work is licensed under a Creative Commons Attribution-NonCommercial-NoDerivatives 4.0 International (CC BY-NC-ND 4.0) License. 